\title{
Formulasi dan Evaluasi Tablet Kaptopril Menggunakan Amilum Umbi Talas dan HPMC yang Dimodifikasi Sebagai Pengisi dan Pengikat Metode Kempa Langsung
}

\author{
Ahmad Sastra Kelana, Aris Perdana Kusuma*, Oktavia Indrati \\ Program Studi Farmasi, Fakultas Matematika dan Ilmu Pengetahuan Alam, \\ Universitas Islam Indonesia \\ *email: arisperdana@uii.ac.id
}

\begin{abstract}
Indonesia is a tropical country which has many potential plants as excipients, like starches and tubers. Amylum of taro tuber (Colocasia esculenta) has the potential to be developed into excipient but its use is limited. The purpose of this study was to optimize the formulation and to evaluate the characteristics of captopril tablets by using amylum of taro tuber and HPMC modified as filler and binder on direct compression method. Amylum of taro tuber was obtained by extraction process, then combined with HPMC by partial pregelatination and co-process method. Variation of the starch was divided into five formulation. The main test included friability test, hardness test, dissolution test, and assay. The data analysis was done by theoretical approach between the evaluation result and the literature to observe the result of the modification formulation. It indicated that the combination of equal amount of taro amylum and microcrystalline cellulose (MCC) $\mathrm{PH}$ $102(50 \%: 50 \%)$ has the best result among others. Friability percentage was $0.17 \pm 0.07 \%$, disintegration time was $12.09 \pm 0.52$ minutes, assay was $97.88 \pm 1.71 \%$ and dissolution test results was $90.65 \pm 4.81 \%$.
\end{abstract}

Keywords: Tablet, Captopril, Co-Process, Partial Pregelatination

\begin{abstract}
ABSTRAK
Indonesia adalah negara tropis yang memiliki banyak tumbuhan yang potensial dikembangkan sebagai bahan tambahan obat seperti pati dan umbi. Amilum dari umbi talas (Colocasia esculenta) berpotensi dikembangkan menjadi bahan tambahan obat tetapi peggunaannya masih terbatas. Penelitian ini bertujuan untuk membuat dan mengevaluasi sediaan tablet kaptopril menggunakan amilum umbi talas dan HPMC yang dimodifikasi sebagai pengisi dan pengikat pada metode kempa langsung. Amilum talas diperoleh melalui proses ekstraksi, kemudian dikombinasi dengan HPMC den gan metode pregelatinasi parsial dan ko-proses. Variasi penggunaan amilum dibedakan menjadi lima formulasi. Pengujian yang dilakukan meliputi evaluasi sifat alir granul sebelum kempa, dan serangkaian evaluasi tablet, yakni uji keragaman bobot, uji keragaman ukuran, uji kerapuhan, uji kekerasan, uji waku hancur, uji disolusi, dan penetapan kadar. Hasil evaluasi menunjukkan bahwa formulasi yang mengandung amilum talas pregelatinasi : mikrokristalin selulosa (MCC) PH 102 (50:50) memiliki hasil evaluasi sifat fisik tablet yang paling baik dilihat dari uji kerapuhan yaitu $0,17 \pm 0,07 \%$, waktu hancur $12,09 \pm 0,52$ menit, penetapan kadar 97,88 $\pm 1,71 \%$ dan hasil uji disolusi $90,65 \pm 4,81 \%$.
\end{abstract}

Kata kunci : Tablet, Kaptopril, Ko-Proses, Pregelatinasi Parsial

Formulasi dan Evaluasi Tablet Kaptopril Menggunakan Amilum Umbi Talas dan HPMC yang Dimodifikasi sebagai Pengisi dan Pengikat Metode Kempa Langsung 


\section{Pendahuluan}

Penggunaan amilum sebagai bahan pengisi dan pengikat memiliki peranan penting dalam pembuatan sediaan tablet (Lawal dkk., 2015; Versino dan García, 2014). Namun demikian, pemanfaatan amilum masih memberikan hasil kerapuhan dan kekerasan yang buruk pada tablet, sedangkan persyaratan suatu sediaan tablet harus memiliki tingkat kerapuhan dan kekerasan yang baik (Nguyen dkk., 2013; Radojevic dan Zavaliangos, 2017). Untuk memperbaiki hal itu maka dapat dilakukan modifikasi fisika dengan pregelatinasi dan ko-proses terhadap amilum (Awaluddin dkk., 2017; Ortega-Toro dkk., 2014).

Pregelatinasi yang dilanjutkan dengan ko-proses terhadap amilum, dapat melibatkan polimer seperti HPMC maupun Na-CMC. Proses ini tidak mengakibatkan perubahan kimia dan terjadi perubahan sifat fisik dari partikel (Kusuma dkk., 2014, 2017). Polimer yang ditambahkan secara ko-proses digunakan untuk meningkatkan daya ikat amilum (Lawal dkk., 2015; Nnamani dan Okonkwo, 2017). Penelitian sebelumnya belum dilakukan formulasi dan evaluasi pada tablet (Awaluddin dkk., 2017). Maka dari itu penelitian ini dilakukan formulasi tablet untuk menguji sejauh mana efektivitas amilum modifikasi koproses yang telah dihasilkan.

Bahan aktif yang digunakan adalah kaptopril, obat hipertensi dengan dosis kecil yang diproses dengan teknik kempa langsung (Kaya dkk., 2016; Saurí dkk., 2014). Berdasarkan hal itu perlu dilakukan penelitian lebih lanjut terkait formulasi dan evaluasi tablet kaptopril menggunakan amilum yang dimodifikasi dengan HPMC sebagai pengisi dan pengikat pada metode kempa langsung.

\section{Tujuan Penelitian}

Tujuan penelitian ini adalah untuk memformulasi dan menguji efektivitas amilum termodifikasi sebagai bahan pengisi tablet kaptopril dengan metode kempa langsung.

\section{Metode Penelitian}

\section{Bahan}

Bahan-bahan yang digunakan adalah umbi talas (Colocasia esculenta (L.) Schott) didapatkan dari pedagang di pasar Pakem, Sleman, Yogyakarta yang diperoleh pada tanggal 20 Februari 2017, kaptopril (Phapros), mikrokristalin selulosa (MCC) PH 102 (Asahi Kasei), HPMC K15, primojel, airosil (PT. Brataco) dan magnesium stearat (Peter Greven). 


\section{Ekstraksi dan Ko-Proses}

Amilum umbi talas dikupas dari kulit luar, kemudian dipotong hingga kecil dan ditambahkan garam dapur $(\mathrm{NaCl})$ sebanyak 100 gram / kilogram, kemudian umbi talas diparut. Hasil parutan ditambahkan air satu setengah bagian atau lebih banyak dari hasil parutan, kemudian disaring dengan kain berpori kecil hingga mengeluarkan air berwarna putih atau eksudat dari talas. Air hasil perasan kemudian didiamkan selama 1x24 jam hingga mengendap, air dibagian atas lapisan endapan dibuang hingga tersisa hanya endapan. Endapan kemudian di oven dengan suhu tidak lebih dari $45^{\circ} \mathrm{C}$ hingga kering dan menjadi amilum. Amilum talas kemudian digerus hingga berbentuk serbuk (Awaluddin dkk., 2017; Zhang dkk., 2017).

Sebelum ditambahkan, HPMC terlebih dahulu dikembangkan dengan air (Aho dkk., 2017). Penelitian ini menggunakan HPMC 3\% atau 3 gram ditambahkan dengan $100 \mathrm{~mL}$ aquades. Setelah ditambahkan aquades yang telah didinginkan, HPMC dihomogenkan menggunakan mixer dan didiamkan hingga mengembang sempurna.

Disiapkan amilum sebanyak 40 gram dan dilarutkan dengan air yang telah dipanaskan sebanyak $100 \mathrm{~mL}$. Larutan HPMC dan larutan amilum kemudian ditambahkan ke dalam satu wadah dan dihomogenkan menggunakan mixer. Hasil campuran kedua larutan tersebut dipindahkan ke dalam wadah dan dikeringkan di oven dengan suhu tidak lebih dari $45^{\circ} \mathrm{C}$ hingga membentuk massa basah. Massa basah diayak dengan ayakan mesh 20, 30, 40 50, dan 60, kemudian dikeringkan kembali hingga kadar air menjadi 5\% (Awaluddin dkk., 2017).

\section{Pembuatan Tablet}

Pembuatan tablet kaptopril menggunakan metode kempa langsung dengan mesin kempa single punch (Korsch). Kempa langsung memiliki keuntungan sebagai cara produksi tablet yang paling mudah dan efisien (Bejugam dkk., 2015; Järvinen dkk., 2013; Meeus, 2011). Penelitian ini menggunakan amilum talas hasil pregelatinasi sebagai bahan pengisi (Tabel 1).

\section{Evaluasi Serbuk}

Evaluasi serbuk yang dilakukan adalah uji waktu alir dan sudut diam. Uji ini dilakukan untuk mengukur kecepatan alir serbuk melalui corong (Ketterhagen, 2015; Saifullah dkk., 2016). 
Tabel 1. Formulasi Tablet Kaptopril dengan Pengisi Amilum Termodifikasi

\begin{tabular}{lccccc}
\hline Bahan & $\begin{array}{c}\text { Formula I } \\
(\mathrm{mg})\end{array}$ & $\begin{array}{c}\text { Formula II } \\
(\mathrm{mg})\end{array}$ & $\begin{array}{c}\text { Formula III } \\
(\mathrm{mg})\end{array}$ & $\begin{array}{c}\text { Formula IV } \\
(\mathrm{mg})\end{array}$ & $\begin{array}{c}\text { Formula V } \\
(\mathrm{mg})\end{array}$ \\
\hline Kaptopril & 12,5 & 12,5 & 12,5 & 12,5 & 12,5 \\
MCC PH-102 & 122 & 73,2 & 61 & 48,8 & 0 \\
Amilum modifikasi & 0 & 48,8 & 61 & 73,2 & 122 \\
Primojel & 12 & 12 & 12 & 12 & 12 \\
Aerosil & 1,5 & 1,5 & 1,5 & 1,5 & 1,5 \\
Magnesium stearat & 2 & 2 & 2 & 2 & 2 \\
\hline \multicolumn{1}{c}{ Total } & 150 & 150 & 150 & 150 & 150 \\
\hline
\end{tabular}

Sejumlah serbuk digunakan dalam uji ini. Sebanyak 60 gram serbuk sampel dimasukkan ke dalam corong uji waktu alir. Tutup corong dibuka sehingga serbuk keluar corong dan jatuh ke bidang datar dan dihitung waktu alirnya menggunakan stopwatch. Dicatat waktu yang diperlukan untuk mengalirkan serbuk melalui corong dan dihitung diameter dan tinggi tumpukan granul.

\section{Evaluasi Tablet}

Uji kekerasan dilakukan terhadap tablet yang telah dikempa. Sebanyak 20 tablet dimasukkan ke alat uji kekerasan (Vanguard YD-2) satu-persatu. Pengukuran berhenti ketika tablet pecah dan kekerasannya dibaca pada alat (Anonim, 2014).

Uji kerapuhan dilakukan terhadap 20 tablet dan dibebasdebukan. Setelah itu ditimbang seksama lalu dimasukkan ke alat uji kerapuhan (Erweka TA-100/TA200). Pengujian dilakukan selama empat menit pada kecepatan 25 putaran per menit dan dibandingkan dengan bobot sebelumnya (Anonim, 2016).

Uji keragaman bobot dilakukan dengan menggunakan 20 tablet yang diambil acak, lalu ditimbang satu persatu. Rerata penimbangan ditentukan kemudian dihitung persentase penyimpangan tiap bobot tabletnya. Selanjutnya dilakukan uji keragaman ukuran terhadap 20 tablet. Pengukuran diameter dan ketebalan tablet menggunakan jangka sorong.

Uji waktu hancur dilakukan dengan memasukkan lima buah tablet ke dalam alat uji (Erweka). Setiap lubang diisi satu tablet. Alat dijalankan sampai semua fraksi pecahan tablet melewati ayakan yang terletak pada bagian bawah alat dan dicatat waktu yang diperlukan sebagai waktu hancur tablet (Anonim, 2016).

Uji disolusi dilakukan dengan alat uji Erweka DT 706 aparatus 2 dengan tipe dayung. Tablet dimasukkan ke dalam alat disolusi yang berisi HCL 0,1 N sebanyak $900 \mathrm{~mL}$ pada suhu $37^{\circ} \mathrm{C}$ dengan 
kecepatan pengadukan 50 RPM selama 30 menit. Pengambilan sampel $5 \mathrm{ml}$ dilakukan pada menit ke $3,5,7,10,15$, 20, dan 30. Kadar kaptopril terdisolusi ditentukan pada spektrofotometer UVVis (Shimadzu U-2810) pada panjang gelombang $205 \mathrm{~nm}$ (Anonim, 2016).

Penetapan kadar bahan aktif dilakukan dengan mengambil 20 tablet kemudian digerus dan ditimbang setara 100 mg kaptopril. Tablet yang telah digerus dimasukkan ke dalam labu takar $100 \mathrm{~mL}$ dan ditambahkan HCL 0,1 N hingga $100 \mathrm{~mL}$. Tablet yang telah dilarutkan kemudian diambil $0,8 \mathrm{ml}$ lalu diencerkan dengan larutan HCL 0,1 N hingga $10 \mathrm{ml}$, hasil pengenceran dibaca pada spektrofometer UV pada panjang gelombang maksimum kaptopril $205 \mathrm{~nm}$ (Anonim, 2016).

\section{Hasil Dan Pembahasan}

\section{Evaluasi serbuk}

Berdasarkan Tabel 2, waktu alir yang telah didapat digunakan untuk menentukan kecepatan alir. Hasil yang didapatkan menunjukkan bahwa kecepatan alir dari seluruh formulasi sangat bagus dan lebih dari $10 \mathrm{~g} /$ detik. Kecepatan alir akan mempengaruhi kecepatan granul mengalir pada hopper menuju lubang die di dalam mesin kempa tablet (Kusuma dkk., 2014). Kecepatan alir yang tinggi diharapkan akan membuat bobot dan dosis tablet yang dihasilkan lebih seragam.

Selain kecepatan alir, sudut diam juga dapat ditentukan dengan pengujian corong alir. Hasil yang didapatkan dikatakan baik karena sudut diam seluruh formula kurang dari $30^{\circ}$. Sudut diam tidak terlalu berkorelasi dengan kecepatan air. Sudut diam terendah yang menggambarkan sifat alir terbaik justru dimiliki oleh serbuk yang mengalir paling lambat. Serbuk yang mengalir paling cepat (formula I) justru memiliki sudut diam paling besar.

Namun demikian kecepatan alir merupakan parameter pengujian sifat alir secara langsung, sehingga hasilnya diharapkan lebih berkorelasi dengan keadaan serbuk sesungguhnya daripada sudut diam.

MCC PH 102 yang berbentuk granul mini dengan ukuran partikel besar, pada pengujian ini, ternyata lebih signifikan meningkatkan sifat alir daripada amilum modifikasi (Edge dkk., 200). Selain itu, amilum modifikasi kemungkinan lebih menyerap kelembaban dari udara dan terjadi peningkatan kohesivitas serbuk sehingga dapat memperburuk sifat alirnya. 
Tabel 2. Evaluasi Serbuk dengan Pengisi Amilum Termodifikasi

\begin{tabular}{cccc}
\hline Formula & Waktu Alir (detik) & Sudut Diam $\left({ }^{\mathbf{0}}\right)$ & Kecepatan alir (g/detik) \\
\hline I & $2,1 \pm 0,1$ & $24,69 \pm 0,54$ & $28,1 \pm 0,8$ \\
II & $3,1 \pm 0,1$ & $24,59 \pm 0,24$ & $19,2 \pm 0,3$ \\
III & $4,1 \pm 0,1$ & $22,54 \pm 0,61$ & $14,5 \pm 0,2$ \\
IV & $4,4 \pm 0,1$ & $25,20 \pm 0,25$ & $13,5 \pm 0,2$ \\
V & $5,4 \pm 0,1$ & $21,23 \pm 0,40$ & $11,0 \pm 0,1$ \\
\hline
\end{tabular}

Tabel. 3 Evaluasi Sifat Fisik Tablet Kaptopril dengan Pengisi Amilum Termodifikasi

\begin{tabular}{|c|c|c|c|c|c|c|}
\hline \multirow{2}{*}{ Formula } & \multirow{2}{*}{$\begin{array}{l}\text { Bobot rata- } \\
\text { rata (mg) }\end{array}$} & \multicolumn{2}{|c|}{ Keragaman Ukuran (mm) } & \multirow{2}{*}{$\begin{array}{c}\text { Kekerasan } \\
\text { (kg) }\end{array}$} & \multirow{2}{*}{$\begin{array}{c}\text { Kerapuhan } \\
(\%)\end{array}$} & \multirow{2}{*}{$\begin{array}{l}\text { Waktu Hancur } \\
\text { (menit) }\end{array}$} \\
\hline & & Diameter & Tebal & & & \\
\hline I & $152,3 \pm 1,34$ & $8,09 \pm 0,008$ & $2,73 \pm 0,05$ & $5,27 \pm 0,23$ & $0,32 \pm 0,21$ & $0,12 \pm 0,01$ \\
\hline II & $154,4 \pm 1,35$ & $8,09 \pm 0,027$ & $2,49 \pm 0,01$ & $4,92 \pm 0,25$ & $0,29 \pm 0,27$ & $1,34 \pm 0,12$ \\
\hline III & $151,6 \pm 2,74$ & $8,07 \pm 0,010$ & $2,38 \pm 0,08$ & $5,57 \pm 0,36$ & $0,17 \pm 0,07$ & $2,51 \pm 0,52$ \\
\hline IV & $148,4 \pm 1,14$ & $8,05 \pm 0,009$ & $2,37 \pm 0,10$ & $4,87 \pm 0,20$ & $0,16 \pm 0,03$ & $13,10 \pm 0,44$ \\
\hline $\mathrm{V}$ & $148,9 \pm 1,29$ & $8,10 \pm 0,013$ & $2,39 \pm 0,03$ & $2,81 \pm 0,16$ & $0,17 \pm 0,06$ & $>15,00$ \\
\hline
\end{tabular}

\section{Evaluasi Tablet}

\section{Uji Keragaman Bobot}

Hasil uji bobot ditampilkan pada Tabel 3. Tablet yang dihasilkan sudah memenuhi persyaratan. Hasil evaluasi dari uji keragaman bobot tersebut ditunjukkan dengan perolehan nilai $\mathrm{CV}$ dari kelima formula kurang dari $5 \%$ dan tidak ada tablet yang bobotnya menyimpang lebih dari 7,5\%. Selain itu berdasarkan nilai SD dari kelima formula menunjukkan hasil pengukuran bobot tablet hampir dikatakan seragam, karena eksipien dari kelima formula terutama amilum modifikasinya memiliki bentuk granul yang sama sehingga ketika di lakukan proses kempa, serbuk yang masuk dari hopper menuju lubang die bobotnya sama.

\section{Uji Keragaman Ukuran}

Pengujian keragaman ukuran dilakukan dengan pengukuran diameter dan ketebalan tablet. Secara umum ukuran tablet seluruh formula, baik itu diameter maupun ketebalan telah seragam.

\section{Uji Kekerasan}

Seluruh formula, kecuali formula V, memiliki rentang kekerasan tablet 4-6 kg. Kekerasan tablet diatur sedemikian rupa agar tahan terhadap tekanan dan goncangan mekanik, namun juga dapat segera hancur begitu kontak dengan air.

Hasil uji kekerasan menunjukan bahwa kelima formula memiliki perbedaan hasil kekerasan pada tiap

Formulasi dan Evaluasi Tablet Kaptopril Menggunakan Amilum Umbi Talas dan HPMC yang Dimodifikasi sebagai Pengisi dan Pengikat Metode Kempa Langsung 
formula dengan menggunakan tekanan kempa yang sama. Hasil tersebut menunjukkan bahwa variasi konsentrasi amilum hasil pregelatinasi dengan $\mathrm{MCC}$ PH 102 mempengaruhi kekerasan tablet.

Hasil pengujian menunjukkan bahwa MCC PH 102 lebih dominan dalam meningkatkan kompaktibilitas tablet, yang diwakili oleh nilai kekerasan. MCC sendiri, baik itu PH 102, 101, maupun seluruh variannya yang merupakan modifikasi selulosa, memang dikenal memiliki kompaktibilitas yang sangat tinggi dibandingkan pengisi lainnya (Edge dkk., 2000; Krok dkk., 2017). Sementara itu, formula $\mathrm{V}$ dengan hanya amilum ko-proses sebagai pengisi, hanya menghasilkan kekerasan yang rendah.

\section{Uji Kerapuhan}

Kelima formula tersebut sudah memenuhi kriteria pada uji kerapuhan yaitu di bawah 1\%. Hasil tersebut menunjukkan bahwa amilum modifikasi yang ditambahkan HPMC dapat meningkatkan kompaktibilitas tablet. Walaupun MCC PH 102 berpengaruh signifikan pada peningkatan nilai kekerasannya, tetapi nilai kerapuhan yang dihasilkan sebanding dengan amilum termodifikasi. Hal ini kemungkinan disebabkan oleh adanya
HPMC yang merupakan polimer dengan daya ikatan yang kuat. Proses penambahan HPMC pada amilum melibatkan air yang dapat mengaktifkan daya ikat dan meningkatkan kekuatan polimernya (Hazarika dan Sit, 2016).

\section{Uji Waktu Hancur}

Hasil pengujian waktu hancur tablet seluruhnya dibawah 15 menit, kecuali formula V. Pengujian ini bertujuan untuk memprediksi kemampuan terdisintegrasi tablet kaptopril dalam cairan lambung maupun usus.

Formula $\mathrm{V}$ memiliki waktu hancur yang lama dikarenakan HPMC yang ada dalam amilum ko-proses akan membentuk lapisan hidrogel jika berinteraksi dengan pelarut atau cairan. Hal ini menyebabkan lamanya waktu hancur dan memperlambat waktu pelepasan obat (Larsson dkk., 2017). Formula V hanya terdapat amilum modifikasi dan tidak ada MCC PH 102. Sementara itu, pada formula yang lain terdapat MCC PH 102 yang membantu disintegrasi tablet karena selain fungsinya sebagai pengisi, bahan tersebut juga bertindak sebagai disintegran. Hal itu dibuktikan dengan waktu hancur pada formula I yang sangat cepat karena tidak ada penggunaan amilum termodifikasi. 
Mekanisme MCC PH 102 yang juga berperan sebagai penghancur dengan cara mengembang dan menyerap air sehingga memberikan kontribusi pada peningkatan waktu disintegrasi tablet (Edge dkk., 2000).

\section{Penetapan Kadar Kaptopril}

Penetapan kadar bahan aktif dalam tablet dimaksudkan untuk mengetahui jumlah kaptopril yang terdapat dalam setiap tablet dan memastikan ketepatan kadarnya sesuai dengan persyaratan.

Tablet kaptopril dipersyaratkan mengandung tidak kurang dari $90 \%$ dan tidak lebih dari $110 \%$ jumlah kaptopril (Anonim, 2016). Seluruh formula diperoleh hasil penetapan kadar sesuai dengan persyaratan (Tabel 4). Tidak terdapat pengaruh bahan pengisi terhadap perolehan kadar.
Tabel 4. Hasil Uji Kadar Kaptopril dengan Pengisi Amilum Termodifikasi

\begin{tabular}{cc}
\hline Formula & Kadar kaptopril (\%) \\
\hline I & $96,67 \pm 0,57$ \\
II & $95,45 \pm 0,99$ \\
III & $97,88 \pm 1,71$ \\
IV & $95,53 \pm 0,73$ \\
V & $98,94 \pm 0,80$ \\
\hline
\end{tabular}

\section{Uji Disolusi}

Uji disolusi dilakukan untuk mengetahui kadar kaptopril yang terlarut pada waktu tertentu. Kriteria untuk persen disolusi agar tablet memenuhi syarat yaitu kadar obat terlarut dalam waktu 20 menit harus larut tidak kurang dari 80\% (Anonim, 2016). Data dan grafik hasil disolusi tablet dapat dilihat pada Gambar 1.

Hasil uji disolusi formula I-IV telah memenuhi persyaratan, yakni terdisolusi tidak kurang dari $80 \%$ dalam waktu 20 menit.

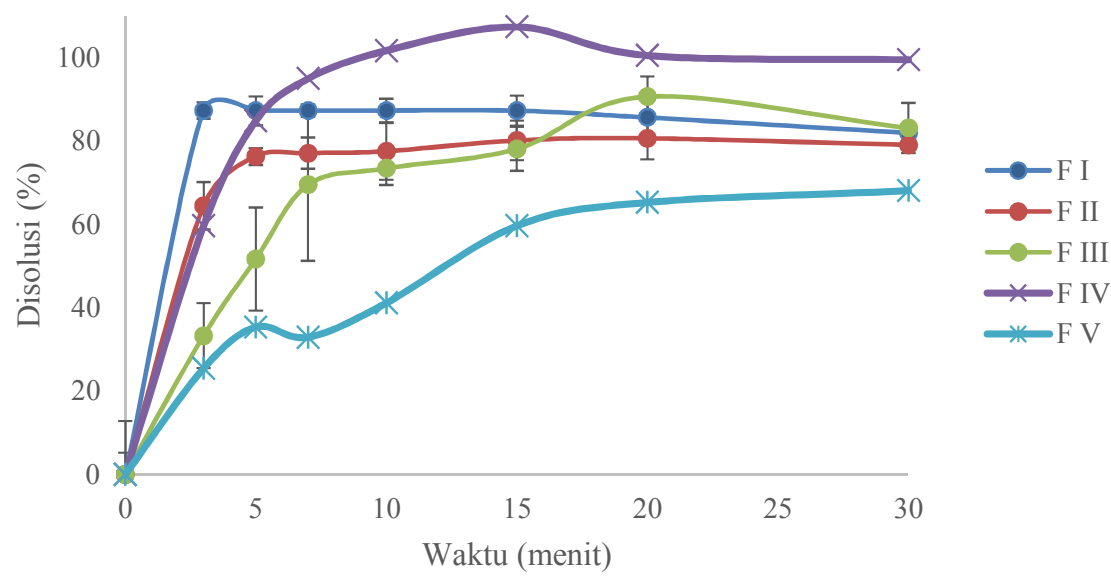

Gambar 1. Grafik Hasil Uji Disolusi Tablet Kaptopril dengan Pengisi Amilum Termodifikasi

Formulasi dan Evaluasi Tablet Kaptopril Menggunakan Amilum Umbi Talas dan HPMC yang Dimodifikasi sebagai Pengisi dan Pengikat Metode Kempa Langsung 
Formula $\mathrm{V}$ tidak memenuhi persyaratan karena dibawah $80 \%$. Hasil ini dimungkinkan karena formula $\mathrm{V}$ yang bahan pengisinya hanya amilum termodifikasi, memiliki lapisan hidrogel yang menyebabkan susahnya medium disolusi menembus tablet sehingga menghambat proses pelarutan bahan aktifnya (Caccavo dkk., 2017).

\section{Kesimpulan}

Berdasarkan penelitian ini, dapat disimpulkan bahwa formula III yang mengandung amilum modifikasi : MCC PH 102 (50:50) memiliki sifat fisik tablet yang paling baik. Penelitian ini juga menunjukkan bahwa amilum termodifikasi dapat digunakan sebagai alternatif pengisi tablet kempa langsung, walaupun masih harus dikombinasikan dengan pengisi lainnya.

\section{Daftar Pustaka}

Aho, J., Halme, A., Boetker, J., Water, J. J., Bohr, A., Sandler, N., Rantanen, J. dan Baldursdottir, S., 2017, The effect of HPMC and MC as pore formers on the rheology of the implant microenvironment and the drug release in vitro, Carbohydrate Polymers, 177, 433-442.

Anonim, 2014, Farmakope Indonesia edisi V, Departemen Kesehatan Republik Indonesia, Jakarta.
Anonim, 2016, The United States Pharmacopeia 39-The National Formulary 34.

Awaluddin, R., Prasetya, A. W., Nugraha, Y., Suweleh, M. F., Kusuma, A. P. dan Indrati, O., 2017, Physical modification and characterization of starch using pregelatinization and co-process of various tubers from Yogyakarta as an excipient, AIP Conference Proceedings, 1823.

Bejugam, N. K., Mutyam, S. K. dan Shankar, G. N., 2015, Tablet formulation of an active pharmaceutical ingredient with a sticking and filming problem: direct compression and dry granulation evaluations, Drug Development and Industrial Pharmacy, 41, 333-341.

Caccavo, D., Lamberti, G., Barba, A. A., Abrahmsén-Alami, S., Viridén, A. dan Larsson, A., 2017, Effects of HPMC substituent pattern on water up-take, polymer and drug release: An experimental and modelling study, International Journal of Pharmaceutics, 528, 705-713.

Edge, S., Steele, D. F., Chen, A., Tobyn, M. J. dan Staniforth, J. N., 2000, The mechanical properties of compacts of microcrystalline cellulose and silicified microcrystalline cellulose, International Journal of Pharmaceutics, 200, 67-72.

Hazarika, B. J. dan Sit, N., 2016, Effect of dual modification with hydroxypropylation and crosslinking on physicochemical properties of taro starch, Carbohydrate Polymers, 140, 269278.

Formulasi dan Evaluasi Tablet Kaptopril Menggunakan Amilum Umbi Talas dan HPMC yang Dimodifikasi sebagai Pengisi dan Pengikat Metode Kempa Langsung 
Järvinen, M., Paaso, J., Paavola, M., Leiviskä, K., Juuti, M., Muzzio, F. dan Järvinen, K., 2013, Continuous direct tablet compression: effects of impeller rotation rate, total feed rate and drug content on the tablet properties and drug release., Drug development and industrial pharmacy, 39, 1802-8.

Kaya, A., Tatlisu, M. A., Kaplan Kaya, T., Yildirimturk, O., Gungor, B., Karatas, B., Yazici, S., Keskin, M., Avsar, S. dan Murat, A., 2016, Sublingual vs. Oral Captopril in Hypertensive Crisis, Journal of Emergency Medicine, 50, 108-115.

Ketterhagen, W. R., 2015, Simulation of powder flow in a lab-scale tablet press feed frame: Effects of design and operating parameters on measures of tablet quality, Powder Technology, 275, 361-374.

Krok, A., Vitorino, N., Zhang, J., Frade, J. R. dan Wu, C. Y., 2017, Thermal properties of compacted pharmaceutical excipients, International Journal of Pharmaceutics, 534, 119-127.

Kusuma, A. P., Fudholi, A. dan Nugroho, A. K., 2014, Optimization Direct Compression's Co - Processed Excipient Microcrystalline Cellulose PH 102 and Povidone ${ }^{\circledR}$ K 30, IOSR Journal of Pharmacy and Biological Sciences, 9, 65-69.

Kusuma, A. P., Syukri, Y., Sholehuddin, R. F., Fazzri, A. N., Romdhonah dan Hakim, R. B. F., 2017, Optimization of microcrystalline cellulose $\mathrm{PH}$ 101, Lactose, and Kollidon ${ }^{\circledR}$ K 30 to obtain co-processed excipient through spray drying, International Journal of Drug Delivery Technology, 7, 83-88.
Larsson, M., Johnsson, A., Gårdebjer, S., Bordes, R. dan Larsson, A., 2017, Swelling and mass transport properties of nanocellulose-HPMC composite films, Materials and Design, 122, 414-421.

Lawal, M. V., Odeniyi, M. A. dan Itiola, O. A., 2015, Effect of thermal and chemical modifications on the mechanical and release properties of paracetamol tablet formulations containing corn, cassava and sweet potato starches as filler-binders, Asian Pacific Journal of Tropical Biomedicine, 5, 585-590.

Meeus, L., 2011, Direct compression versus granulation, Pharmaceutical Technology Europe, 23, 21.

Nguyen, T. H., Morton, D. A. V dan Hapgood, K. P., 2013, Application of the unified compaction curve to link wet granulation and tablet compaction behaviour, Powder Technology, 240, 103-115.

Nnamani, N. D. dan Okonkwo, T. J. N., 2017, Optimization of metronidazole tablet formulation using Manihot utilissima starch and a combination of processing techniques, Future Journal of Pharmaceutical Sciences, 3, 65-70.

Ortega-Toro, R., Jiménez, A., Talens, P. dan Chiralt, A., 2014, Properties of starch-hydroxypropyl methylcellulose based films obtained by compression molding, Carbohydrate Polymers, 109, 155165.

Radojevic, J. dan Zavaliangos, A., 2017, On the Post-Compaction Evolution of Tensile Strength of Sodium Chloride-Starch Mixture Tablets, Journal of Pharmaceutical Sciences, 106, 2088-2096.

Formulasi dan Evaluasi Tablet Kaptopril Menggunakan Amilum Umbi Talas dan HPMC yang Dimodifikasi sebagai Pengisi dan Pengikat Metode Kempa Langsung 
Saifullah, M., Yusof, Y. A., Chin, N. L. dan Aziz, M. G., 2016, Physicochemical and flow properties of fruit powder and their effect on the dissolution of fast dissolving fruit powder tablets, Powder Technology, 301, 396-404.

Saurí, J., Millán, D., Suñé-Negre, J. M., Pérez-Lozano, P., Sarrate, R., Fàbregas, A., Carrillo, C., Miñarro, M., Ticó, J. R. dan García-Montoya, E., 2014, The use of the SeDeM diagram expert system for the formulation of Captopril SR matrix tablets by direct compression,
International Journal of

Pharmaceutics, 461, 38-45.

Versino, F. dan García, M. A., 2014, Cassava (Manihot esculenta) starch films reinforced with natural fibrous filler, Industrial Crops and Products, 58, 305-314.

Zhang, B., Li, X., Xie, Q., Tao, H., Wang, W. dan Chen, H. Q., 2017, Preparation and characterization of non-crystalline granular starch and corresponding carboxymethyl starch, International Journal of Biological Macromolecules, 103, 656-662. 